\title{
Internet-Based Cultural Enrichment in the Polish Language Classroom
}

\author{
Kinga Kosmala and Erik Houle \\ University of Chicago
}

\begin{abstract}
Most introductory and intermediate textbooks for Polish, currently in use, are written in Poland and intended for intensive language study in-country where the "little-c" cultural component is inherent and immediate in an intensive language program. One of the most widely used textbooks in North America is the series, Hurra!!! po polsku I, II, III. This textbook is based on a communicative approach to language pedagogy and consists of thematic chapters according to aspects of life and culture in everyday society. The intent of the Hurra!!! po polsku series is that students will experience Poland while learning the language. This presents a problem to educators of Polish in the United States. Numerous communicative exercises presuppose acquaintance with the target culture while providing little in the way of input. We have found that students have difficulty relating to many exercises that carry specific cultural information. Our project is based on two specific goals: first, to decrease the amount of time spent in class to explain culture-specific aspects of the textbook; and second, to spare our students at least some amount of the usual culture shock one experiences when traveling to Poland. In this report, we describe a website, exercises, and activities we developed to accompany the textbook.
\end{abstract}

Keywords: Polish as second language, Web-based learning, flipped classroom, "littlec" culture, Polski z nami, cultural enrichment, cultural proficiency.

Tmagine a scenario where an American instructor of Polish asks her American students to use their newly acquired adjectival endings to describe osiedle (neighbourhood), Polonez (a Polish make of car, no longer produced), or Jacobs Krönung in Polish. Then imagine the instructor wondering why the students are not able to complete the exercise. After probing, she realizes that the exercise is futile because these objects of everyday Polish life are completely foreign to her American students. It is a common scenario in the foreign language classroom, and one that we believe requires more attention. As instructors of Polish, we endeavour to introduce the students to the intricacies of Polish grammar, vocabulary, pronunciation, and culture, but we realize we had to include yet another aspect of the language: culture. We make the distinction between so-called "high brow" culture and "low brow" culture. We define the latter as the everyday cultural items, traditions, and formulaic language, which, when unknown to the student/traveller, can create culture shock. "Little-c" culture describes the patterns of everyday living. It can include universal tasks such as the correct 
way to order food in a restaurant, how to get on a bus, or where to go shopping. For Polish and other East European languages and cultures, some very specific cultural concepts would be related to housing, the packaging of goods, and to food, to name a few (Brooks 210). Given the time constraints of the academic year and the significant amount of grammar and challenges the Polish language poses for learners, we understood that we had to somehow address this issue in an effective and inventive way. Having received a grant from the University of Chicago Language Center for Language Teaching and Learning for a project entitled "Internet-Based Cultural Enrichment in the Polish Language Classroom," we had two specific goals for the project: first, to decrease the amount of time spent in class to explain some specific cultural aspects; and second, to spare our students at least some of the usual culture shock one experiences when travelling to Poland.

\section{RATIONALE}

Most introductory and intermediate textbooks for Polish, currently in use in North America, are written in Poland and intended for intensive language study in-country where the "little-c" cultural component is inherent and immediate in an intensive language program. One of the most widely used textbooks in the United States is the series, Hurra!!! po polsku I, II, III (Hurray in Polish I, II, III). The textbook is designed around a communicative approach to language teaching and learning. The textbook consists of chapters that are thematically organized according to aspects of everyday society life and culture in Poland. The major principle of the Hurra!!! po polsku series is to immerse students in a life in Poland via language learning. This type of a cultural immersion presents problems in a second-language Polish classroom outside Poland, in our case, in the United States. Numerous communicative exercises presented in the textbook presuppose students' knowledge and understanding of the Polish culture. Importantly, very little cultural input is provided in the textbook itself. We have found that students have difficulty relating to many exercises that contain very specific cultural information with which students are unfamiliar.

As justification for the project about which we report here, we turned to The Standards for Foreign Language Learning in the 21st Century in the National Standards in Foreign Language Education Project. In this report, "culture" is defined as "the philosophical perspectives, the behavioral practices, and the products - both tangible and intangible - of a society" (National Standards 47). Additionally, we embraced the 3P (Perspectives, Practices, Products) approach to culture, which emphasizes learning and teaching as a set of fundamental values, attitudes, and beliefs, as opposed to 
the mere introduction of disconnected cultural products and practices (Cutshall 32). The discussion about various methods of teaching culture in a foreign language classroom has been going on for years, but consensus on the most effective techniques of incorporating culture in the foreign language teaching process has not been reached. Language instructors are constantly searching for and employing varied approaches that effectively integrate culture into their instruction and foster students' cultural awareness.

According to the 2015 report from the Institute of International Education (IIE), only $14.9 \%$ of U.S. students who received a bachelor's degree in 2015 studied abroad. Moreover, only 1\% of undergraduates complete long-term study abroad programs, because the majority of U.S. study abroad programs last less than eight weeks (Institute of International Education). This lack of direct exposure to Polish culture underlines the necessity for culture to constitute an indispensable part of foreign language instruction.

The theoretical model of the three Ps, that is, Practices, Perspectives, and Products, works particularly well when the digital media is incorporated into it. Throughout our numerous years of experience as foreign language educators, we have come to realize that occasional, and often random, inputs from a textbook, infrequent movie nights, or field trips to ethnic restaurants do not offer sufficient exposure to Polish culture. We have also found, and later seen it confirmed numerous times in foreign language research, that presenting products and practices as fragmented, disconnected pieces of information, rather than as elements of a cultural entity can often lead to the reinforcement of stereotypes. Over years of instruction, it has become clear to us that culture should be incorporated early, at the introductory level. Research shows, and our own experience corroborates, that only a small percentage of Polish language students continue to the advanced level (Furman et al.).

Students often achieve relative Polish language proficiency but lack cultural knowledge. That can lead to unfortunate situations, as native Polish speakers are more willing to forgive a language mistake, rather than a serious cultural faux pas. With all of this in mind, and following the 3P model, we designed our project to emphasize a thorough understanding of Polish culture through its many aspects of daily life patterns, such as housing, food, traditions, and the formulaic language associated therewith. The addition of digital media in our classes allowed for all of these elements to be integral parts of our classes. The layout of the project is based on the textbook Hurra!!! po polsku but is purposely adaptable to other textbooks or materials. Rather than adhere to one textbook, we chose a more general approach to presenting the aspects of culture associated with each thematic topic. 


\section{PROJECT DESCRIPTION}

When harnessed correctly, the Internet is a veritable treasure trove of potential cultural activities for the language learner. From Internet stores to YouTube, the interactive possibilities are infinite. Instructors can utilize these resources to complement the instruction while challenging the students to apply linguistic and cultural knowledge in virtual "real world" activities in the target language. Keeping the activities outside of the classroom ensures that more time is used in the classroom for using the language in a meaningful way. This project was inspired by the description of portfolio assignments for Russian in Garza (20).

While we chose mostly YouTube videos for our project, we did not want our students to simply go online and find random materials. Our materials were always carefully screened for cultural and classroom appropriateness. Each unit was designed to fulfill the model of products, practices, and perspectives. We must admit, however, that products and practices were easier to adapt, while perspectives constituted a challenge for us. Each unit and its accompanying videos was chosen to broaden our students' knowledge of Polish daily life, culture, history, geography, traditions, etc. (see the Unit on Województwa).

Our further goal with the project is to have the students create a cultural portfolio about Poland as they advance in their knowledge of language and culture. In this task we followed the model described in Schulz in which she proposed creating and building cultural portfolios (18). These portfolios help students develop awareness and knowledge of the target culture and help them to avoid "broad generalizations or stereotyping" (Schulz 35). The students are responsible for maintaining the project throughout the course of their study of Polish.

The goal of our project was to design and implement a host of broad Internet-based tasks, which complement the variety of Polish textbooks in use and provide the learner with more cultural input. Each chapter in both Hurra!!! po polsku I and Hurra!!! po polsku II are accompanied by up to three multi-skill tasks, which reinforce the cultural themes and grammar of that chapter. The main page of the website (see Figure 1) includes one module per thematic unit, roughly corresponding to the chapters of the textbook. 
Figure 1. Main Page of www.polskiznami.com

\section{POLSKI Z NAMI IEsson auzzes neour}

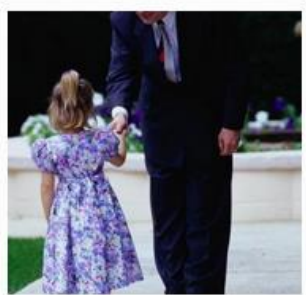

LEKCJA 1

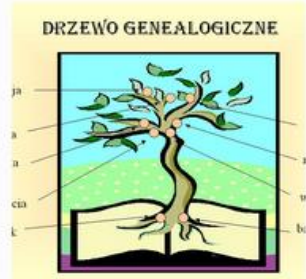

LEKCJA 4

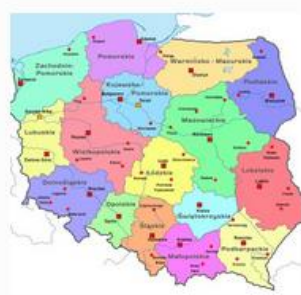

LEKCJA 2

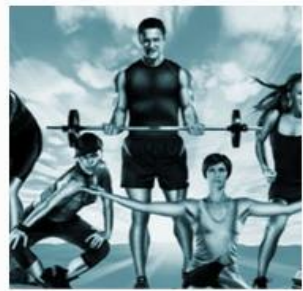

LEKCJA 5

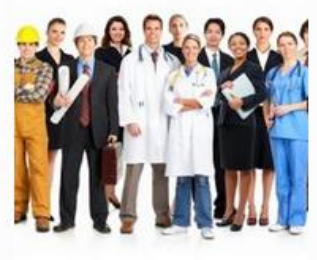

LEKCJA 3

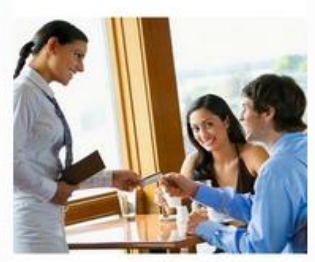

LEKCJA 6

For each unit we identified three aspects of "little-c" culture that might have warranted explanation, for example województwo (province), centrum handlowe (shopping mall), or product packaging. We then found representations of each item on the Internet in the form of simple advertisements, video clips, or websites, which were easily comprehensible to our students. We chose audiovisual materials that combined universally understood elements along with culturally relevant components to facilitate the objective. Each advertisement and video focused on one of the three aforementioned aspects of Polish culture. For each visual material we developed a series of questions to measure comprehension. These questions were structured in a variety of ways: true/false, multiple choice, and fill-inthe-blank. Cloze exercises, in which words or phrases have been removed from a written text and students are asked to fill in the blanks by listening to the complete version of the text, were also included. Questions that required one-word or shorter responses were written in Polish. Longer responses were written in English.

At the beginning of each unit the cultural component was assigned to correspond with the order of the textbook. In addition to regular written 
homework, students completed a set of simple online tasks. On average, students were able to complete the tasks within twenty minutes per cultural element. Answers were automatically collected, filtered, and exported in Excel according to instructor through the Web-based platform Typeform. The instructors then corrected, graded, and provided feedback for the submissions as part of the student's overall grade. As a final component of the entire chapter folder, students were required to write about or present their experience; for instance, students were asked to write about or present what they purchased in an Internet store. These reflection exercises were prompted by questions to guide the process more effectively.

In the first-year textbook, chapter 9 introduces the students to various kinds of stores/making purchases/customer service. The Internet-based tasks for this chapter then challenge the students to acquaint themselves, in various ways, with the differences between typical shopping venues in the USA and in Poland. This is seen in Figure 2 below. The objective here is twofold: students apply linguistic proficiency in relevant "real-world" contexts while gaining more cultural proficiency in the language-learning journey.

\section{Figure 2. Sample Quiz in the Chapter 9 Module}

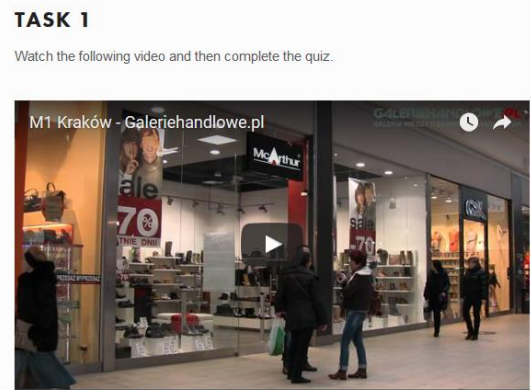

We chose Squarespace and Typeform as the platforms for the project for a variety of reasons. The inclusion of Typeform enabled us to upload quizzes. Typeform also enables the instructor to collect and filter student responses for evaluation. The website is independent of university course management 
systems in order to avoid the burden of adapting it to the various systems at other institutions.

One module in the project introduces the students to various kinds of stores/making purchases/customer service. The Internet-based tasks for this chapter then challenge the students to acquaint themselves, in various ways, with the differences between typical shopping venues in the USA and in Poland. Task one is based on a YouTube video that presents a newly constructed shopping mall in Kraków. Students are tasked to identify visible differences between types of stores, businesses, and services. Students are often shocked to find that Polish malls offer baby-sitting services and house grocery stores. Task two introduces the students to a typical Polish neighbourhood grocery store. Questions similar to those in the previous task are posed. Task three asks students to take a virtual tour of an online Polish supermarket store. This task acquaints students with differences in currency, pricing, weights and measures, and packaging. Here students learn that eggs come in packages of ten and pasteurized milk is unrefrigerated and kept on shelves, among other things surprising to American students.

The project was implemented in the first-year Polish classes at three institutions in Chicago. Two institutions follow the quarter system and one is on the semester system. In addition to the differences in scheduling and contact hours/week at these institutions, there are other factors that contribute to varying paces and objectives. In order to accommodate these factors the project was implemented at varied rates and with different emphases. At each institution the project was well received by the students. The students generally agreed that even in today's world of readily accessible technology, this added cultural component of the curriculum introduces an aspect of the culture they would not be able to encounter otherwise, unless they actually travelled to Poland.

\section{EVALUATION AND DRAWBACKS}

The project is inscribing itself into general trends in foreign language pedagogy, and it follows the national standards and the suggestions outlined for instructors of foreign language. The project is far from being complete, as we will have to dedicate more time to it and improve the technological prowess. We found, however, that even in its limited scope, presentation, and accessibility, this modest endeavour yielded many positive results. Most obvious among these results was the fact that we did not have to devote precious class time to constant cultural digressions. More time was therefore spent on communicative tasks.

In our view there are two distinct pressures exerted on foreign language instructors of less commonly taught languages: the need to develop effective 
teaching materials that demonstrate an acquaintance with current technology; and an ability to survive and adapt to issues of enrollment, recruitment, and changes in priorities in higher education. As we contend with contact hour reduction, we look at other instructors' efforts in maintaining quality pedagogy, at their innovative approaches in blended learning, and at "flipped classrooms." A project such as ours is born out of these pressures and can contribute to the greater community of foreign language instruction, if only in ideas. Ultimately, we would like to share this project and collaborate with other instructors of Polish to develop it not just in the U.S. but everywhere in the world where Polish is taught.

\section{Works Cited}

Brooks, Nelson. "Teaching Culture in the Foreign Language Classroom." Foreign Language Annals, vol. 1, no. 3, 1968, pp. 204-17.

Cutshall, Sandy. "More Than a Decade of Standards: Integrating 'Cultures' in Your Language Instruction." The Language Educator, vol. 7, no. 3, 2012, pp. 32-36.

Furman, Nelly, et al. "Enrollments in Languages Other Than English in United States Institutions of Higher Education, Fall 2009." Modern Language Association, Dec. 2010, apps.mla.org/pdf/2009 enrollment survey.pdf. Accessed Sept. 2016.

Garza, Thomas J. "Keeping It Real: Intensive Instruction and the Future of Russian Language and Culture in U.S. Universities." Russian Language Journal, vol. 63, 2013, pp. 7-24.

Institute of International Education. "2015 Fast Facts," http://www.iie.org/Research-and-Publications/Open-Doors/Data/FastFacts\#.WLdDtkkixWd. Accessed 23 Feb. 2016.

National Standards in Foreign Language Education Project. The Standards for Foreign Language Learning in the 21st Century. Allen Press, 1999.

Schulz, Renate. "The Challenge of Assessing Cultural Understanding in the Context of Foreign Language Instruction." Foreign Language Annals, vol. 40, no. 1, 2007, pp. 9-26. 